\title{
EL RECURSO DE NULIDAD LABORAL COMO HERRAMIENTA DE CONTROL DE LAS EXIGENCIAS IMPUESTAS POR LA SANA CRÍTICA A PROPÓSITO DE LA SENTENCIA ROL 1068-2010 DE LA CORTE DE APELACIONES DE SANTIAGO
}

\section{CRISTIÁn Contreras Rojas*}

\section{INTRODUCCIÓN}

El nuevo sistema de enjuiciamiento laboral ha establecido el recurso de nulidad como única herramienta impugnatoria que procede contra la sentencia definitiva dictada en el juicio oral, determinando que una de sus causales es la vulneración manifiesta de las normas sobre apreciación de la prueba según las reglas de la sana crítica, sin que el legislador haya clarificado los alcances del control jurisdiccional que en esta sede puede llevar a cabo el tribunal de alzada. Así, los pronunciamientos reiterados por distintas Cortes de Apelaciones en esta materia, han ido en la línea de evitar a toda costa la intromisión en la apreciación de la prueba que ha llevado a cabo el tribunal de la instancia, pues este sería el único llamado a desarrollar esta labor. Sin embargo, una reciente sentencia de la Novena Sala de la Iltma. Corte de Apelaciones de Santiago, dictada en la causa Rol 1068-2010, postula que este tribunal sí tiene la facultad de entrar a apreciar la valoración de la prueba que ha hecho el juez del trabajo, pues, de lo contrario, la causal de nulidad relativa a la sana crítica resultaría inoperante.

Es por ello que, a propósito de dicho pronunciamiento, en este trabajo me remitiré a realizar algunas referencias acerca de los límites $-\mathrm{y}$ de paso, las exigencias mínimas- que se le imponen al examen que las Cortes de Apelaciones deben realizar, conociendo de un recurso de nulidad fundado en la vulneración de las normas sobre la sana crítica, asumiendo desde ya que dicho control debe tratarse de una revisión que constituya una garantía efectiva del respeto de los derechos de los litigantes, de modo que no es posible que se limite a una mera revisión de los aspectos de forma de la sentencia, y que al mismo tiempo tampoco es admisible que, en dicho afán, se convierta de hecho en una segunda instancia jurisdiccional.

Profesor de Derecho Procesal de la Universidad de Talca (Chile). Magíster en Derecho Constitucional, mención Derecho Procesal Constitucional de la misma Universidad. Correo electrónico: ccontreras@utalca.cl. El autor agradece la enorme colaboración y apoyo prestado por Ximena Baeza B. en la preparación de este trabajo. 


\section{1) PRESENCIA de la sana CRÍtiCA EN EL PROCEDIMIENTO LABORAL CHILENO}

Sabido es que el modelo de valoración de la prueba previsto por el sistema jurídico-procesal de nuestro país fue cambiando su fisonomía durante el transcurso del siglo XX, pasando desde un mecanismo caracterizado por la desconfianza en las aptitudes del juez, la necesidad de contener las enormes atribuciones que le confería el procedimiento inquisitivo ${ }^{1}$ y la fascinación por el poder del legislador, quien valoraba la prueba de un modo previo y abstracto $^{2}$ (sistema legal, tasado o tarifado); a un modelo en que se abrieron las puertas a la apreciación personal y racional del sentenciador, apertura que, claro está, nunca estuvo -ni estará- exenta de ciertas restricciones y limitaciones (sistema de sana crítica). En efecto, si bien durante el siglo pasado se contemplaban solo algunos procedimientos especiales en los que se consagraba el modelo de sana crítica y de modo casi emblemático la prueba pericial se valoraba (y se valora) de esta forma en el juicio civil, el nuevo siglo y la justicia 2.0 que vio nacer, han hecho de este sistema la regla general, tal como se aprecia en el procedimiento penal (art. 297 CPP), de familia (art. 32 Ley No19.968) y laboral (art. $456 \mathrm{CT}$ ), así como en el proyecto de nuevo CPC, en el que se sigue la misma línea ${ }^{3}$.

Así, en lo que respecta al proceso laboral -sobre el que se centra este trabajo-, desde sus orígenes contempló un sistema de apreciación racional de la prueba, tendencia que se reforzó y precisó con el advenimiento del Código del Trabajo de 1987, normativa en la que se indicó expresamente que el juez debía apreciar la prueba rendida en juicio conforme a la sana crítica (arts. 429 y 430). Esta disposición se mantiene prácticamente intacta hasta el día de hoy, pues no se vio afectada por el cambio del sistema procesal que se llevó a cabo en los últimos años ${ }^{4}$.

\footnotetext{
Horvitz Lennon, María Inés / López Masle, Julián (2004). Derecho Procesal Penal Chileno. Santiago: Editorial Jurídica de Chile, Tomo II, 660 pp., p. 146.

2 Cerda San Martín, Rodrigo (2008). Valoración de la prueba. Sana crítica. Santiago: Librotecnia, 148 pp., p. 9.

3 En efecto, el artículo 266 del proyecto indica: "Los jueces apreciarán la prueba de acuerdo a las reglas de la sana crítica. En consecuencia, no podrán contradecir los principios de la lógica, las máximas de la experiencia y los conocimientos científicamente afianzados, salvo texto legal que expresamente contemple una regla de apreciación diversa".

$4 \quad$ El actual artículo 456 del Código del Trabajo señala que: "El tribunal apreciará la prueba conforme a las reglas de la sana crítica. Al hacerlo, el tribunal deberá expresar las razones jurídicas y las simplemente lógicas, científicas, técnicas o de experiencia, en cuya virtud les asigne valor o las desestime. En general, tomará en especial consideración la multiplicidad, gravedad, precisión, concordancia y conexión de las pruebas o antecedentes del proceso que utilice, de manera que el examen conduzca lógicamente a la conclusión que convence al sentenciador".
} 
De la sola lectura del artículo 456 del Código del Trabajo resulta evidente que el sistema de la sana crítica no admite de ninguna manera la posibilidad que el tribunal lleve a cabo actuaciones antojadizas y/o arbitrarias, que no se condigan con el respeto de los derechos fundamentales de los litigantes. De este modo, el sistema se encuentra construido sobre el reconocimiento expreso de ciertas barreras limitantes al desborde de las atribuciones del sentenciador, las que clásicamente son el respeto de las reglas básicas impuestas por la lógica y las máximas de la experiencia, a las que los sistemas procesales chilenos del siglo XXI han agregado la observancia de los conocimientos científicamente afianzados 5 . Necesariamente a lo anterior debemos añadir la obligación del tribunal de expresar con claridad y precisión el desarrollo del fundamento de la decisión adoptada, lo que permite el control de la misma y su aceptación por los afectados, como asimismo, la adecuada presentación de recursos por las partes del litigio, según sea el caso $^{6}$. En esta perspectiva, el proceso laboral ha impuesto expresamente a los jueces -desde hace más de veinte años- el deber de explicar cuáles son las razones y fundamentos jurídicos, lógicos, científicos, técnicos y de experiencia, sobre los que cimientan sus decisiones, todo lo cual debe quedar consignado en la sentencia definitiva, pues ella debe contener "[e]l análisis de toda la prueba rendida, los hechos que estime probados y el razonamiento que conduce a esta estimación" (art. 459 No4 CT).

Sumado a lo anterior, en el sistema de la sana crítica nos encontramos con una ausencia de normas legales que le asignen valor a las pruebas rendidas en juicio, toda vez que será el juez el que deberá realizar este ejercicio en cada caso concreto, mediante una ponderación acuciosa, imparcial y racional de la prueba $^{7}$, de acuerdo a su experiencia y a los pos-

$5 \quad$ El artículo 297 del CPP expresa: "Los tribunales apreciarán la prueba con libertad, pero no podrán contradecir los principios de la lógica, las máximas de la experiencia y los conocimientos científicamente afianzados", lo que se reitera por el artículo 32 de la ley No 19.968 que creó los Tribunales de Familia.

$6 \quad$ Nuestra Corte Suprema ha indicado en relación con este aspecto: "Los tribunales y la doctrina han hecho hincapié en esta obligación de motivar o fundamentar las sentencias, por cuanto tal exigencia no solo dice relación con un asunto exclusivamente procesal, referido a la posibilidad de recurrir, que implica impugnar una resolución de manera de evitar errores y arbitrariedades - derecho consagrado en la Carta Fundamental, que importa la idea del racional, justo y debido proceso que debe alcanzarse en la sentencia- sino porque, además, se relaciona con un tema externo a la procesabilidad indicada, que se enmarca en la necesidad de someter al examen que puede hacer cualquier ciudadano de lo manifestado por el juez y que hace posible, asimismo, el convencimiento de las partes en el pleito, evitando la impresión de arbitrariedad al tomar estas conocimiento del porqué de una determinación”. Corte Suprema. 22 de julio de 2010. Rol No451-2009. "Cáceres Fuentes, Alfonso con Cáceres Riquelme, Viviana". Disponible en http://www.poderjudicial.cl/modulos/TribunalesPais/ TRI_esta402.php? rowdetalle=AAANo PAAkAA BUGJAAD\&consulta $=100 \&$ glosa $=\&$ causa $=451 / 2009 \&$ numcua $=25776 \&$ secre $=$ UNICA [fecha de visita 23 de diciembre de 2010] . Cerda (2008) 28. 
tulados de la lógica y la ciencia, explicitando las motivaciones de su decisión $^{8}$, de modo que ella pueda ser entendida y compartida por cualquier persona.

\section{2) EL RECURSO DE NULIDAD LABORAL Y SU VINCULACIÓN CON LA SANA CRÍTICA}

En lo que dice relación con la sentencia definitiva dictada en el juicio oral, el modelo recursivo previsto por la nueva justicia del trabajo estableció un régimen restringido de impugnación, optando por extirpar la posibilidad de recurrir de apelación en contra de dicha resolución y centrando todas sus energías en el recurso de nulidad, símil del previsto para el sistema de enjuiciamiento criminal, y al igual que este, de derecho estricto9 ${ }^{9}$. Ello se justificó por la enorme importancia que se le otorgó a los principios de oralidad, inmediación y celeridad en esta reforma procesal, que llevaron al legislador a establecer, en resumidas cuentas, un procedimiento de única instancia. Así, durante la tramitación de la reforma procesal laboral, la Comisión de Trabajo de la Cámara de Diputados dejó en claro la incompatibilidad de la apelación con el modelo de justicia que se pretendía establecer, indicando que "un recurso de instancia como el recurso de apelación (y la revisión de los hechos que lo caracteriza) no se aviene con el objetivo y naturaleza del juicio oral ni con la lógica que introduce tal tipo de procedimiento en materia de apreciación probatoria, especialmente con uno de sus aspectos más relevantes: que solo puede reconocerse al juez ante quien se produce, en un acto único e irrepetible, la facultad de establecer los hechos que se dan por probados y ponderar su mérito probatorio. La repetición de la prueba en segunda instancia no es concebible en este tipo de procedimientos"10. En efecto, como lo sostiene el profesor Orellana, la prueba en sede laboral se encuentra revestida por los principios de oralidad, inmediación, concentración, bilateralidad, aportación de prueba por las partes (limitado por las abundantes y muy importantes facultades que

Horvitz / López (2004) 150.

Dicha decisión ha querido ser revisada por moción de los senadores Pérez y Longueira, toda vez que en el mes de junio de 2010 se presentó un proyecto de ley tendiente a reincorporar el recurso de apelación a la justicia laboral, poniendo al principio de la doble instancia por sobre los de inmediación y celeridad. Dicho intento ha sido calificado por el profesor Tapia como un desmantelamiento del nuevo modelo de juicio del trabajo, pues la doble instancia surge como incompatible con el juicio oral. Tapia Guerrero, Francisco (2010). "Admisibilidad del recurso de nulidad laboral”. Revista Laboral Chilena, No188, pp. 60-69, p. 66.

10 Biblioteca del Congreso Nacional de Chile (2006). Historia de la Ley 20.087. 947 pp. Disponible en http://www.bcn.cl/histley/lfs/hdl-20087/HL20087.pdf [fecha de visita 20 de diciembre de 2010], p. 87. 
en este aspecto se le han otorgado al juez) y oficialidad ${ }^{11}$, varios de los cuales resultan incompatibles con la posibilidad de una segunda instan$\mathrm{cia}^{12}$

En el mismo sentido, la profesora Lanata apunta que la justicia del trabajo estableció un sistema de recursos "destinados a revisar la validez de las resoluciones, impidiendo que un tribunal que no ha conocido o recepcionado la prueba emita un pronunciamiento sobre las cuestiones de hecho discutidas en el juicio, las que quedan definitivamente asentadas por el a quo"13. A ello agrega que la imposibilidad de la Corte de pronunciarse sobre el componente fáctico del proceso es la única apreciación coincidente con el sistema de la sana crítica. En esta perspectiva, resulta indiscutible que existe un vínculo entre el sistema de valoración de la prueba por el que optó el legislador laboral y el sistema de impugnación establecido, más aún, cuando entre las causales del recurso de nulidad se dispone expresamente que procederá cuando la sentencia definitiva haya sido pronunciada con infracción manifiesta de las normas sobre la apreciación de la prueba conforme a las reglas de la sana crítica -art. 478 letra b) CT-, herramienta que viene a constituir una garantía expresa de los derechos fundamentales de las partes del pleito, en el sentido de velar por la adecuada y suficiente razonabilidad, justificación y fundamento de la sentencia definitiva dictada en el litigio.

\section{3) Sentencia dictada por la Iltma. Corte de Apelaciones de SANTIAGO, EN CAUSA ROL No 1068-2010}

La Novena Sala de la Iltma. Corte de Apelaciones de Santiago -con fecha 8 de noviembre de 2010 - se pronunció a partir de la interposición de un recurso de nulidad en contra de la sentencia definitiva dictada por el Segundo Juzgado de Letras del Trabajo de esa ciudad, conociendo de un procedimiento monitorio por reclamación de multa iniciado por la empresa Tecnomix S.A. en contra de la Inspección Comunal del Trabajo Santiago Sur Oriente. En dicha resolución, el juez

\footnotetext{
11 Orellana Torres, Fernando (2009). Comentarios al nuevo proceso laboral. $3^{\text {a }}$ edición actualizada. Santiago: Librotecnia, 334 pp., pp. 178 y ss.

12 En la misma perspectiva, el profesor Tapia señala que "[e]l juicio de hecho es el juicio de la instancia... Todo explica que el juicio de instancia sea revisado a través de un recurso de nulidad, que se diferencia esencialmente de la antigua apelación laboral, en cuanto a que, al quedar establecidos los hechos con el carácter de inamovibles, solo se puede impugnar la valoración que de ellos se ha hecho en la sentencia, si se estima que se ha infringido las reglas de la sana crítica o a través de las causales de invalidación en la forma o en el fondo...”. TAPIA (2010) 60.

13 Lanata Fuenzalida, Gabriela (2010). “¡Puede el juez lograr el conocimiento exigido por la ley si no ha recibido la prueba?”. Revista Laboral Chilena, No 191, pp. 76-86, p. 78.
} 
laboral rechazó la solicitud de dejar sin efecto la multa cursada por la Inspección en contra de la empresa reclamante, por lo que la actora recurrió de nulidad alegando como causa principal de la misma, la infracción manifiesta de las normas sobre la apreciación de la prueba conforme a la sana crítica, tal como lo indica el artículo 478 letra b) del Código del Trabajo.

En definitiva, la Corte de Apelaciones decidió acoger el recurso de nulidad deducido por la demandante, invalidando la sentencia pronunciada por el juez del trabajo y dictando la sentencia de reemplazo respectiva, en la que -examinando las pruebas rendidas-acogió el reclamo de la empresa y dejó sin efecto la multa impuesta.

Ahora bien, dejando de lado los aspectos de fondo del asunto que escapan al análisis procesal que se plantea en este trabajo, el tribunal señaló el fundamento adjetivo de su decisión en el considerando tercero de la sentencia, en el que indicó:

"TERCERO: Que el inciso segundo del articulo 456 del Código del Trabajo señala, en relación a las normas que regulan la sana critica, que el juez "deberá expresar las razones jurídicas y las simplemente lógicas, cientificas, técnicas o de experiencia, en cuya virtud les asigne valor o las desestime. En general, tomará en especial consideración la multiplicidad, gravedad, precisión, concordancia y conexión de las pruebas o antecedentes del proceso que utilice, de manera que el examen conduzca lógicamente a la conclusión que convence al sentenciador". Luego, del análisis del fallo se comprueba que el sentenciador, en el considerando cuarto, al ponderar la prueba rendida ha conculcado los principios de la lógica que, de haberlos respetado, necesariamente habría concluido que el reclamo debía acogerse. Es cierto que el juez del trabajo pondera libremente la prueba, pero esta libertad no es absoluta, pues tiene las importantes limitaciones a que se refiere el citado artículo 456 del Código Laboral, de suerte que un razonamiento que se aparte de la lógica, de la ciencia o de la experiencia, vicia el fallo si ello ha tenido influencia sustancial en lo que se decide. $Y$ no es efectivo, como algunos pretenden, que el tribunal de alzada, conociendo de un recurso de nulidad, no pueda entrar a apreciar la valoración de la prueba que hizo el sentenciador del fondo pues la única forma de analizar si la sentencia incurrió o no en el vicio a que se refiere la letra b) del artículo 478 del Código del Trabajo es analizando la ponderación de los medios probatorios que hizo el tribunal de la instancia y concluir asi si se respetaron los parámetros del citado articulo 456 del mismo cuerpo legal. Sostener lo contrario importaria, ni más ni menos, que la causal referida sería, en la práctica, inoperante. Es evidente que si se dice que el juez valoró la prueba apartándose de la lógica, de las máximas de la experiencia o de los conocimientos cientificos, la única manera de resolver tal alegación es, precisamente, estudiando 
la valoración hecha por el referido sentenciador y hacer las conclusiones respectivas"14.

Sin embargo, esta interpretación amplia de las atribuciones que tendría la Corte conociendo de un recurso de nulidad laboral fundado en la citada causal, no fue compartida por todos los miembros de la Sala, pues la decisión fue acordada con el voto disidente de la Ministro Ravanales, quien estuvo por rechazar el recurso de nulidad. Ella consideró que el recurrente -más que alegar la vulneración de las normas de la sana crítica- objetó la valoración que el juez del trabajo había hecho de la prueba rendida, además de lo cual, indicó que no se apreciaba en el fallo una transgresión notoria u ostensible a las reglas de la lógica, la experiencia o la ciencia. A saber:

“A) Que, en definitiva, la parte recurrente ha atacado la valoración de la prueba que el juez de la instancia ha hecho, lo que no es posible en un recurso de esta naturaleza, en que el tribunal de alzada hace un control de legalidad del fallo y no de su mérito.

B) Que la causal esgrimida, la de la letra b) del articulo 478 del Código del Trabajo, se refiere a una violación manifiesta de las normas sobre apreciación de la prueba conforme a las reglas de la sana critica, es decir, solo autoriza a esta Corte a observar si notoriamente hay una vulneración de esta naturaleza que atente contra la lógica, las máximas de la experiencia o los conocimientos cientificos, nada de lo cual ocurre en la especie, en que del considerando cuarto de la sentencia impugnada aparece claramente que el tribunal del fondo hizo una valoración de la prueba, en uso de sus facultades exclusivas y excluyentes, sin que ostensiblemente haya vulnerado las referidas reglas de valoración".

\section{4) ANÁLISIS DE LA SENTENCIA}

La Corte de Apelaciones de Santiago plantea un asunto de capital importancia en la sentencia arriba reseñada, toda vez que nos lleva a reflexionar acerca de la determinación del ámbito de atribuciones de control que el nuevo modelo de justicia laboral le ha entregado a la Corte de Apelaciones que conoce de un recurso de nulidad fundado en la violación manifiesta de las normas que impone la sana crítica.

14 Corte de Apelaciones de Santiago. 8 de noviembre de 2010. Rol No1068-2010. "Tecnomix S.A. con Inspección Comunal del Trabajo”. Disponible en http://corte.poderjudicial.cl/ SITCORTEPORWEB/?opc_menu=7 [fecha de visita 28 de diciembre de 2010], pp. 2-3. 
En efecto, primeramente el tribunal de alzada nos recuerda que si bien el juez del trabajo se encuentra ajeno a normas que le señalen el valor que le debe otorgar a las pruebas incorporadas al juicio, no es menos cierto que en su ejercicio de ponderación debe respetar las limitaciones que le impone la lógica, la ciencia y la experiencia, de modo que si su razonamiento contradice estos postulados, su fallo será susceptible de anulación por la respectiva Corte de Apelaciones. Luego, la decisión de mayoría postula que -a fin de controlar el cumplimiento de las exigencias que establece la sana crítica- es posible que el tribunal de alzada entre a apreciar la valoración de la prueba que ha llevado a cabo el sentenciador del fondo, ya que esa sería la única forma de darle efectivo sentido y aplicación a la letra b) del artículo 478, interpretación que no fue compartida por todos los ministros de la Sala y, que tampoco constituye la norma general en los pronunciamientos que sobre el particular han emitido otras Cortes de Apelaciones.

Parece obvio que la esfera de atribuciones que el modelo de enjuiciamiento le ha entregado a la Corte en esta materia, dice relación con la causal de procedencia del recurso de nulidad que aquí se invoca. En este sentido, la norma legal dispone que será posible anular el fallo del juez laboral, cuando en él existiere una infracción manifiesta de las normas sobre apreciación de la prueba conforme a la sana crítica. Dicho de otro modo, se exige la concurrencia de una transgresión al deber de fundar el fallo mediante un razonamiento que se ajuste a la lógica, la experiencia y la ciencia, incumplimiento que debe resultar claro, patente o visible.

Pero ¿qué tan clara o manifiesta deberá ser la infracción a las normas de la sana crítica? ¿Habrá querido el legislador limitar el examen de la infracción a una constatación que se lleve a cabo mediante la simple la lectura de la sentencia, de modo que el actuar del tribunal de alzada se restringa únicamente a verificar si el fallo contiene un ejercicio de valoración de la prueba incorporada al juicio? $\mathrm{O}$ ¿será necesario que la Corte indague acerca de las motivaciones que llevaron al tribunal de la instancia a valorar la prueba de la forma en que lo hizo y analice si los razonamientos en que apoya su decisión se ajustan a la sana crítica, de modo que con dicho fin pueda apreciar la valoración de los elementos probatorios, tal como lo pretende el fallo comentado?

Evidentemente, optar por una solución u otra implica restringir o extender las facultades que la Corte de Apelaciones tiene en esta materia, y de paso, aceptar los efectos perniciosos que ambas traen aparejadas.

La visión restringida de las atribuciones de la Corte, pero mayoritariamente sostenida por nuestra jurisprudencia, exige que la vulneración de la sana crítica sea palmaria -tal como lo expresa la disidencia de la sentencia en comento- de modo que la infracción debe expresarse "en 
forma evidente y notoria"15, pudiendo detectarse con "la sola lectura de la sentencia"16. Así, partiendo de la base de que los principios y reglas sobre las que se ha erigido el sistema procesal laboral indican que el tribunal de alzada carece de toda facultad vinculada con la discusión sobre el mérito de la prueba rendida y su valoración -facultad que se le ha entregado de forma exclusiva y excluyente al tribunal del trabajo ${ }^{17}-$, a la Corte solo le cabría constatar visualmente que la sentencia definitiva cuenta con un razonamiento de apreciación para dar por cumplidas las exigencias de la sana crítica. Dicho de otra forma, la sentencia solo podría ser anulada cuando carezca absolutamente de un ejercicio de fundamentación y/o de apreciación de la prueba, o cuando contando con este, la vulneración de la lógica, la experiencia o la ciencia sea de tal magnitud, que el tribunal constate la existencia de un desajuste claro, que salte a la vista ${ }^{18}$.

El problema de esta opción radica en que, sin que la ley lo disponga expresamente, el tribunal de alzada autolimita de forma peligrosa sus potestades de control, pudiendo transformar este examen una mera formalidad que de ninguna manera cumple con el fin de velar por el respeto irrestricto de los derechos de los justiciables por parte del tribunal de la instancia. Es así, como las Cortes han sostenido que de la sola lectura del fallo se colige que la prueba fue correctamente analizada y valorada de acuerdo a la sana crítica -sin que se aprecie falta a la lógica o a las máxi-

15 Corte de Apelaciones de Valdivia. 14 de enero de 2010. Rol No84-2009. "Contreras Solís, Rosa con Ortiz Arias, Sergio". Disponible en http://corte.poderjudicial. cl/ SITCORTEPORWEB/?opc_menu=7 [fecha de visita 09 de enero de 2011], p. 1. En el mismo sentido: Corte de Apelaciones de Talca. 21 de junio de 2010. Rol No52-2010. "Cervela con Parra". Disponible en http://corte.poderjudicial.cl/ SITCORTEPORWEB/?opc_menu=7 [fecha de visita 12 de enero de 2011], p. 2;

16 Corte de Apelaciones de Talca. 19 de julio de 2010. Rol No99-2010. "Sociedad Prestadora de Servicios Maquena Ltda. con Inspección Provincial del Trabajo de Curicó”. Disponible en http://corte.poderjudicial.cl/SIT CORTEPORWEB/?opc_menu=7 [fecha de visita 10 de enero de 2011], p. 16. En el mismo sentido: Corte de Apelaciones de Talca. 2 de agosto de 2010. Rol No101-2010. "Forestal Celco S.A. con Inspección Provincial del Trabajo de Curicó". Disponible en http://corte.poderjudicial.cl/SITCORTEPORWEB/?opc_ menu=7 [fecha de visita 06 de enero de 2011], pp. 8-9; Corte de Apelaciones de Talca. 20 de agosto de 2010. Rol No112-2010. "Roldán con Corporación de Capacitación y Educación Industrial y Minera". Disponible en http://corte.poderjudicial.cl/ SITCORTEPORWEB/?opc_menu=7 [fecha de visita 22 de diciembre de 2010], p. 13; Corte de Apelaciones de Talca. 24 de agosto de 2010. Rol No127-2010. "Rojas Morales, Fabiola con Iltre. Municipalidad de Longaví". Disponible en http://corte.poderjudicial. cl/SITCORTEPORWEB/?opc_menu=7 [fecha de visita 7 de enero de 2011], p. 8.

17 Corte Apelaciones de Antofagasta. 8 de noviembre de 2010. Rol No98-2010. "Avendaño con Tecnologías Cobra Sociedad Anónima”. Disponible en http://corte.poderjudicial. cl/SITCORTEPORWEB/?opc_menu=7 [fecha de visita 28 de diciembre de 2010], pp. 10 y ss. En el mismo sentido, C.A. DE Chillán. Rol No30-2009, p. 7.

18 Corte de Apelaciones de Talca. 4 de octubre de 2010. Rol No176-2010. "Schwartz Godoy, Mauricio con Industria Sigala y Compañía Ltda.”. Disponible en http://corte.poderjudicial.cl/ SITCORTEPORWEB/?opc_menu=7 [fecha de visita 13 de enero de 2011], p. 3. 
mas de la experiencia-, sin entregar ninguna explicación de cómo arriban a esa convicción, situación que desde mi perspectiva, no era la que el legislador tenía en mente al establecer este modelo de control jurisdiccional y privar a las partes del recurso de apelación ${ }^{19}$.

Por otra parte, la perspectiva sostenida por la Corte de Apelaciones de Santiago en la causa Rol No1068-2010, nos invita a extender las facultades que el tribunal puede ejercer para controlar el cumplimiento de las exigencias de la sana crítica, pudiendo incluso "apreciar la valoración de la prueba que hizo el sentenciador del fondo". O sea, se postula que el tribunal de alzada no debería restringirse a llevar a cabo un análisis que se satisfaga con la simple lectura de la sentencia definitiva objeto de estudio, pues ello resulta insuficiente de acuerdo a los fines específicos que se han establecido para este control. Dichos fines, están dados por el aseguramiento del respeto de la lógica, la ciencia y la experiencia en la decisión adoptada por el juez laboral, lo que exige algo más que llevar a cabo un examen visual del fallo, pues el error -aunque atentatorio contra la sana crítica- no siempre será de una entidad tal que aparezca de la sola lectura de la sentencia dictada por el juez del fondo.

Por ende, este enfoque amplía las facultades de la Corte, propugnando un análisis más exhaustivo, que haga de este examen un efectivo control por parte del tribunal de alzada. Sin embargo, el peligro de esta visión amplia radica en que se le permitiría a la Corte analizar los motivos que llevaron al juez del trabajo a otorgarle preferencia a una prueba por sobre otra, al tolerar una apreciación de la valoración de la prueba rendi$\mathrm{da}$, circunstancia que deja la puerta abierta para realizar una revisión del componente fáctico que ha quedado acreditado en el juicio oral, transformándose, de esa manera, en un juez de segunda instancia. En efecto, no es posible admitir que el recurso de nulidad constituya una instancia o que su interposición permita que la Corte de Apelaciones respectiva realice un análisis de toda la prueba, así como de los hechos que han quedado acreditados. Es claro que el nuevo modelo de justicia laboral cuenta solo con una instancia.

\section{A MODO DE CONCLUSIÓN}

Como ya se ha indicado, la sana crítica no implica que el juez pueda adoptar las decisiones que le señale su sola intuición o arbitrio, ya que debe respetar las tres limitaciones que se le han impuesto, así como ex-

19 Corte de Apelaciones de Rancagua. 16 de septiembre de 2010. Rol No120-2010. "Cuevas Gutiérrez, Oscar con Iltre. Municipalidad de Pichidegua”. Disponible en http://corte. poderjudicial.cl/ SITCORTEPORWEB/?opc _ menu=7 [fecha de visita 13 de enero de 2011], p. 4 
presar razonada y fundadamente cuales son los motivos de sus sentencias. No debemos olvidar, que el sistema de valoración de la sana crítica no se satisface con que en la sentencia definitiva el tribunal de la instancia haga una simple relación o especie de listado de las pruebas incorporadas al proceso, sino que debe realizar un análisis que cumpla con las exigencias del modelo ${ }^{20}$.

Los elementos de la esencia del sistema de la sana crítica se verían abiertamente trastrocados si no existiera la posibilidad de revisar de forma seria y efectiva la decisión adoptada a través de los recursos establecidos, ya que si los mecanismos de impugnación son tan limitados que no permiten un adecuado examen del fallo por parte del superior jerárquico, de modo que la exigencia de fundamentación se transforme en una cuestión meramente formal o en la reiteración de frases sacramentales, se estaría estableciendo tácitamente un sistema de valoración de la prueba conforme a la íntima convicción del juez. Dicho de otra forma, no basta -para cumplir con las exigencias del modelo- con que el sistema procesal establezca limitaciones y exigencias a las decisiones adoptadas por el sentenciador, sino que este se completa cuando es posible que dichas decisiones sean revisadas suficiente y adecuadamente por el superior jerárquico. De esta manera, la posibilidad de que el superior jerárquico revise la decisión del tribunal de la instancia, hace que este modelo esté marcado por una libre valoración relativa de la prueba ${ }^{21}$. El problema se suscita porque este control de parte del tribunal superior -que aparece como imprescindible para el éxito del sistema de justicia, pero por sobre todo, para el respeto de los derechos de los litigantes- puede desbordarse y convertirse de hecho en una segunda instancia, y de este modo entrar en franca contradicción con el principio de inmediación, uno de los pivotes fundamentales de la nueva justicia del trabajo ${ }^{22}$.

En síntesis, en el modelo vigente no es permisible que el tribunal de nulidad lleve a cabo una valoración de la prueba rendida en juicio, pues ello se opone a las bases fundamentales del actual procedimiento laboral. Lo que sí está llamado a revisar, es que en la instancia se hayan respetado

20 Así lo ha indicado la Corte de Apelaciones de Valparaíso: "De la lectura del fallo se aprecia, que el sentenciador en los considerandos cuarto y quinto hace una enumeración de la prueba aportada por las partes, para luego en el motivo séptimo señalar que en conformidad a la prueba rendida, a la luz de los principios de la sana crítica, tiene por acreditados ciertos hechos, sin proceder a realizar un análisis de la prueba ni el razonamiento que conduce a esa conclusión, lo que tampoco lleva a cabo en los considerandos octavo al décimo primero (sic), en que solo concluye ciertos supuestos sin analizar ni ponderar prueba alguna...". Corte de Apelaciones de Valparaíso. 18 de octubre de 2010. Rol No480-2010. "Labbé con Villegas". Disponible en http://corte.poderjudicial.cl/SITCORTE PORWEB/?opc_ menu=7 [fecha de visita 21 de diciembre de 2010], p. 2.

21 Cerda (2008) 38.

22 Horvitz/López (2004) 153. 
los postulados de la lógica, la experiencia y la ciencia, y que la decisión sea debida, coherente y razonadamente fundamentada. El tribunal superior debe constatar que en el razonamiento que le sirve de base al fallo del juez laboral se haya respetado la lógica, las máximas de la experiencia y los conocimientos científicamente afianzados, lo que debe quedar expresado en la formulación de la sentencia definitiva, tarea de verificación que exige un análisis conciso y detallado de la construcción de las argumentaciones que han llevado al juez a sentenciar en uno u otro sentido, y que evidentemente va más allá de verificar que en la sentencia se ha realizado una simple relación de las pruebas rendidas y se ha cumplido con incluir la frase sacramental: "Que con los medios de prueba señalados precedentemente, apreciados según las normas de la sana critica, se tiene por acreditado que...".

\section{BIBLIOGRAFÍA}

- Biblioteca del Congreso Nacional de Chile (2006). Historia de la Ley 20.087. 947 pp. Disponible en http://www.bcn.cl/histley/lfs/ hdl-20087/HL20087.pdf [fecha de visita 20 de diciembre de 2010]

- Cerda San Martín, Rodrigo (2008). Valoración de la prueba. Sana critica. Santiago: Librotecnia, 148 pp.

- Horvitz Lennon, María Inés / López Masle, Julián (2004). Derecho Procesal Penal Chileno. Santiago: Editorial Jurídica de Chile, Tomo II, 660 pp.

- Lanata Fuenzalida, Gabriela (2010). “¿Puede el juez lograr el conocimiento exigido por la ley si no ha recibido la prueba?”. Revista Laboral Chilena, No191, pp. 76-86.

- Orellana Torres, Fernando (2009). Comentarios al nuevo proceso laboral. $3^{a}$ edición actualizada. Santiago: Librotecnia, 334pp.

- Tapia Guerrero, Francisco (2010). "Admisibilidad del recurso de nulidad laboral". Revista Laboral Chilena, No188, pp. 60-69, p. 66. 